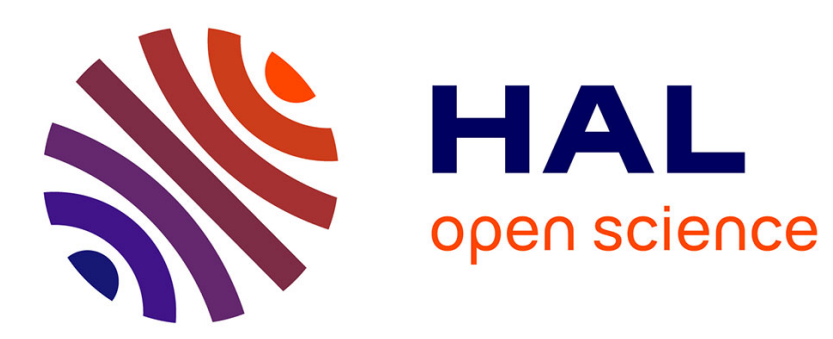

\title{
Correlates of two different physical activity recommendations in a German sample of 14-16-year-old boys and girls
}

Jens Bucksch, Holger Fuhrmann

\section{- To cite this version:}

Jens Bucksch, Holger Fuhrmann. Correlates of two different physical activity recommendations in a German sample of 14-16-year-old boys and girls. Journal of Public Health, 2010, 18 (4), pp.413-423. 10.1007/s10389-010-0319-9 . hal-00535308

\section{HAL Id: hal-00535308 \\ https://hal.science/hal-00535308}

Submitted on 11 Nov 2010

HAL is a multi-disciplinary open access archive for the deposit and dissemination of scientific research documents, whether they are published or not. The documents may come from teaching and research institutions in France or abroad, or from public or private research centers.
L'archive ouverte pluridisciplinaire HAL, est destinée au dépôt et à la diffusion de documents scientifiques de niveau recherche, publiés ou non, émanant des établissements d'enseignement et de recherche français ou étrangers, des laboratoires publics ou privés. 


\title{
Correlates of two different physical activity recommendations in a German sample of 14-16-year-old boys and girls
}

\author{
Jens Bucksch • Holger Fuhrmann
}

Received: 27 April 2009/Accepted: 9 February 2010/Published online: 6 March 2010

(C) Springer-Verlag 2010

\begin{abstract}
Aim The aim of this study was to examine whether the correlates of physical activity (PA) differed as a function of two different PA recommendations: (1) the Fitness Recommendation, i.e., the improvement of cardiovascular fitness by $3 \times 20 \mathrm{~min} /$ week of vigorously intense PA and (2) the health-enhancing PA (HEPA) concept such as the emphasis on the important benefits to health and fitness by performing $5 \times 60 \mathrm{~min} /$ week of moderately intense PA.

Subjects and Methods A cross-sectional design was used. In a sample of 524 adolescents $(50.2 \%$ males, mean age = 15.0), we quantified different (demographic/biological, psychological, behavioural) self-reported correlates of PA as well as compliance with the PA recommendations. Sexspecific multivariate logistic regression models were used to identify correlates of fulfiling the two PA recommendations. Results Multivariate analyses revealed differences between the correlates and PA-specific Recommendations. For boys, only the Fitness Recommendation was significantly associated with psychosocial variables (self-efficacy and behavioural change strategies) and membership in a sports club. For girls, membership in a sports club was significantly associated with both PA recommendations. However, this association was positive with respect to the Fitness
\end{abstract}

\footnotetext{
J. Bucksch $(\square)$

Department of Sport and Exercise Science,

University of Stuttgart,

Allmandring 28,

70569 Stuttgart, Germany

e-mail: jens.bucksch@sport.uni-stuttgart.de

H. Fuhrmann

Institute of Sportsociology,

German Sport University Cologne,

Cologne, Germany
}

Recommendation and negative with respect to the HEPA Recommendation.

Conclusion Our results provided some preliminary indication that correlates differ depending on specific recommendations in 14-16-year-old boys and girls. Moreover some variability with regard to sex was observed.

Keywords Physical activity recommendations.

Correlates $\cdot$ Health-enhancing physical activity $\cdot$ Fitness

\section{Introduction}

Physical activity (PA) during adolescence is an important public health issue. Regular PA is associated with various health benefits (Strong et al. 2005). Nevertheless, the exact dose of PA to prevent detrimental health outcomes remains vague, especially with respect to children and adolescents (Twisk 2001). Recently, there has been a growing number of PA recommendations in the context of public health. Based on epidemiologic studies, two types of PA recommendations have been introduced: (1) an exercise prescription that emphasises the improvement of cardiovascular fitness and (2) the fact that PA of moderate intensity provides important benefits to health and fitness (Pate 2007); currently, the latter recommendation has been well established in the health-enhancing PA (HEPA Recommendation) concept. The United Kingdom Health Education Authority (UK-HEA) established a recommendation based on the HEPA framework for children and adolescents. The UK-HEA recommends $1 \mathrm{~h}$ per day of at least moderate intensity for adolescents (Cavill et al. 2001). A second important recommendation (Fitness Recommendation) that focuses on fitness was introduced at the International Consensus Conference on Physical Activity Guidelines: 
adolescents should engage in three or more sessions per week of activities that last $20 \mathrm{~min}$ or more at a time and that require moderate to vigorous levels of exertion (Sallis and Patrick 1994). The prevalence of adherence to the different recommendation types varies widely. In addition, this variation depends on both the use of measurement methods (Pate et al. 2002) as well as the operationalisation of these guidelines (Olds et al. 2007). In Germany, there are only a few (self-reported) representative datasets available for PA. Based on the guidelines provided by the HEPA Recommendation, about $25-30 \%$ of adolescent boys and about $17-18 \%$ of adolescent girls are sufficiently active (Currie et al. 2004; Richter and Settertobulte 2003). Based on the guidelines provided by the Fitness-Recommendation, approximately $65 \%$ of $11-17$-year-old boys and $44 \%$ of $11-$ 17-year-old girls were sufficiently active (Lampert et al. 2007). For both recommendations, a socioeconomic status (SES) gradient was obvious in girls and boys (Lampert et al. 2007; Richter and Settertobulte 2003).

However, a steep decline of activity levels occurs in adolescence (Sallis 2000). In addition, even though a growing number of well-documented PA interventions do exist, their successes have been shown to be limited (Van Sluijs et al. 2007). Understanding the factors that influence physical activity can facilitate the design of a more effective PA intervention. There have been several reviews describing the correlates of adolescent PA. One semi-quantitative review (Sallis et al. 2000) and one gender-specific systematic review should be highlighted (Biddle et al. 2005). Both reviews identified variables from different categories that are consistently associated with PA: demographic/biological (e.g., age), psychological (e.g., selfefficacy, understanding the pros and cons of exercise), behavioural (e.g., sedentary behaviour, organized sports), social/cultural (e.g., social support) and physical environment (e.g., opportunities to exercise). The authors concluded that because significant variables were found in all categories of correlates, PA is a complex behaviour and interventions must consider all of these variables (Sallis et al. 2000). Another important finding from Sallis and colleagues (2000) was the lack of consistency across studies. One obvious conclusion refers to the potential confounding or moderating variables. In the meantime, there is a growing body of literature describing sex-specific analyses to consider as the predominant moderator (Vilhjalmsson and Kristjansdottir 2003). Biddle and colleagues (2005) concluded that modifiable correlates for adolescent girls clustered around "positive psychology", organized sports involvement and the family. Another review showed that the mode of walking (e.g., for exercise and recreational walking, walking to get to and from places, and total walking) moderates the association with environmental attributes (Owen et al. 2004). Another study examined whether the correlates of youth PA differed as a function of structured vs. unstructured PA and concluded that the structured-unstructured distinction of PA might serve as a potential moderator (Spink et al. 2006). Further studies found that different correlates contribute to explain PA behaviour within different contexts (De Bourdeaudhuij et al. 2005; Timperio et al. 2006). More research is needed to systematically examine the importance of single correlates for specific intensities of PA. Therefore, the role of different PA recommendations seems to be underserved and must be addressed, since these recommendations are often used as an evaluation outcome of interventions. In particular, identifying the extent to which sex moderates the role of specific correlates within these recommendations is required (Sallis et al. 2000; Vilhjalmsson and Kristjansdottir 2003).

The main aim of this study, therefore, was to fill gaps in previous research by

(1) examining whether or not demographic/biological (e.g., BMI), psychological (e.g., self-efficacy) correlates and behavioural attributes (e.g., sedentary behaviour) are involved differently in moderately intense compared to vigorously intense PA, with respect to corresponding PA recommendations, and by

(2) comparing sex-specific patterns of correlates for the two PA recommendations.

\section{Methods}

\section{Sample selection}

We decided to study adolescents within a small age range (14-16-year olds) because a study group defined by a broader age range in the adolescent years would have been too heterogeneous with respect to biological and psychological changes. A cross-sectional design was used. We identified all junior high schools $(n=25)$ in Bremen, Germany, and drew a random sample of schools. Eighteen junior high schools were contacted, and seven of them participated. In these self-selected junior high schools, all ninth graders were invited to participate $(n=656)$. Junior high schools in Germany comprise three different levels of education: "Gymnasium", which is the English equivalent of grammar school; "Realschule" or intermediate secondary school; and "Hauptschule" or secondary general school. The distribution of ninth graders in these three main levels in our study reflected the local distribution in Bremen. The enquiry was ruled out class-wide. The response rate was $96 \%$ and resulted in a sample of 630 adolescents $(50.5 \%$ males, mean age $=15.0 ; \mathrm{SD}=0.67)$. Respondents completed a self-administered questionnaire assessing potential 
correlates, including demographic/biological, psychological and behavioural correlates as well as compliance with PA recommendations. The project was approved by the supervisory school authority of Bremen, by the head of each school, and by each class teacher. The students and parents were informed before participation, and students participated voluntarily. Some participants were excluded because of unanswered questions, but a major bias was not probable because the variables of interest (e.g., PA recommendations, sex) did not significantly differ between the excluded and the included students. The present analyses comprised 524 adolescents.

\section{Instruments}

All instruments were evaluated in a pilot test with 130 students $(46.9 \%$ boys; mean age $15.5 ; \mathrm{SD}=0.6)$ from schools that were not included in the main study. The applicability of the questionnaire was confirmed.

\section{Physical activity assessment}

The PA assessment was based on a validation study (Prochaska et al. 2001). The Fitness Recommendation corresponded to PA of vigorous intensity and referred to a youth-specific guideline (Sallis and Patrick 1994). The participants reported the number of days during the (1) past 7 days and (2) for a typical week they participated in at least $20 \mathrm{~min}$ of vigorously intense PA. Vigorously intense PA was defined as "usually makes you sweat", and some examples were given to illustrate this guideline. The two items were averaged to form a composite measure. A score of three or more days per week engaging in 20-min bouts of vigorously intense PA was considered fulfilment of the Fitness Recommendation. The reliability $(\mathrm{ICC}=0.67)$ and validity $(r=0.37, p=0.01)$ have been previously reported for American youths (Prochaska et al. 2001).

The HEPA Recommendation was measured in a similar way (Prochaska et al. 2001) and also referred to an international consensus (Cavill et al. 2001). The adolescents reported the number of days they had accumulated 60 min of PA during the past 7 days and for a typical week. Physical activity was defined broadly as "[it] increases your heart rate and makes you get out of breath some of the time", and examples were given (e.g., skateboarding, commuting to school, dancing, playing soccer). The intensity level was not specified. A score of 5 or more days per week accumulating in $60 \mathrm{~min}$ or more of moderate to vigorously intense PA was considered as fulfilment of the HEPA Recommendation. The reliability $(\mathrm{ICC}=0.77)$ and validity $(\mathrm{r}=0.40, \mathrm{p}=0.001)$ have been previously reported for American youths (Prochaska et al. 2001).

\section{Potential correlates of PA}

\section{Demographic/biological correlates}

Type of school as an indicator of school education level was determined by the interviewer and classified into the level of school education. The Family Affluence Scale (FAS) was a four-item measure of family wealth. This scale was developed in the WHO Health Behaviour in School-aged Children Study as an alternative measure of socioeconomic status (SES). The FAS was derived by identifying the levels of wealth based upon 'family item' ownership of a car, van or truck $(0,1,2$ or more), whether the child has his or her own bedroom $(0=$ no; $1=$ yes $)$, the number of family holidays in the last 12 months $(0,1,2$ or more), and the number of computers owned by the family $(0,1,2$ or more). The pattern of answers was classified as low, middle and high SES, according to a summation score of $0-3,4-5$ and 6-7, respectively (Richter 2005). Weight status was calculated from self-reported height and weight. Germanspecific age- and gender-specific cutoff values were applied to the body mass index (kilograms/square meters) to define normal weight, overweight and obesity (Kromeyer-Hauschild et al. 2001). These thresholds followed the IOTF (International Obesity Task Force) cutoff values, with normal weight defined below the $90^{\text {th }}$ age-specific percentile, overweight defined as a BMI between the 90th and 97th age-specific percentile and obesity defined as above the 97th age-specific percentile (Cole et al. 2000).

\section{Psychological correlates}

A more detailed description of the assessment of the psychological correlates can be found elsewhere (Bucksch et al. 2008). In brief, self-efficacy was assessed on a 5-point scale by 12 items from an exercise scale for adults. Reliability and construct validity were reported to be good (Fuchs and Schwarzer 1994). Self-efficacy was measured by asking how confident a person was to be physically active under difficult demands. The internal consistency was $\alpha=0.84$. Perceived pros ( 13 items) and cons ( 15 items) of being physically active were examined using a 5-point scale by asking respondents to rate the personal importance they felt of the possible effects of PA. Internal consistency for pros was $\alpha=0.87$ and for cons was $\alpha=0.80$. The behavioural and cognitive change strategies were the covert and overt strategies that people used to progress through the stages of change within the framework of the transtheoretical model (Prochaska and Velicer 1997). We adapted a well-proven English instrument (Rhodes et al. 2004) to the German language. We tested this scale for its comprehensibility in a sample of convenience of 14-16year olds. Afterwards the pilot test mentioned above was 
applied to all scales. The change strategies were finally investigated by 38 items on a 5-point scale. Cronbach's alphas were: $\alpha=0.89$ for behavioural change strategies and $\alpha=0.86$ for cognitive change strategies. Self-rated health was assessed by a single item measure. Adolescents indicated whether their health was "excellent", "good", "fair" or "poor". This item has been a useful measure of emotional health in large epidemiological surveys (Idler and Benyamini 1997).

\section{Behavioural correlates}

The questions on the membership in a sports club and commuting to school were derived from the Karlsruher Aktivitätsfragebogen (Bös et al. 2002). Participants reported whether they were members of a sports club. Three categories were summarised (current member, member in the past, never member). To assess active commuting to school, the interviewees indicated the general mode of transport to commute to school. Going by bike or on foot was categorised as active commuters, and going by bus, driving a car or driving a scooter was collapsed into the category of non-active commuters. Questions from the Health Behaviour in School-aged Children Study on TV viewing, computer use and doing one's homework (Currie et al. 2001) were used to estimate time spent performing sedentary activities. The summation of all three items resulted in an index that represented sedentary time in hours per week. Categories of sedentary behaviour were formed by using tertiles of the time spent in sedentary behaviour distributed among all participants (low: $\leq 3.9 \mathrm{~h} /$ day; middle: $>3.9-5.9$; high: $>5.9$ ).

Data analysis

Survey items of the psycho-social correlates (i.e., behavioural and cognitive change strategies, self-efficacy, pros and cons) were collapsed into two categories: (1) "never", "seldom", "not at all confident", "somewhat confident", "not important" and "a little bit important"; (2) "occasionally", "often", "repeatedly", "moderately confident", "very confident", "completely confident", "somewhat important", "quite important" and "extremely important".

The HEPA Recommendation, the Fitness Recommendation and all other correlates of interest were compared by sex using independent t-tests for metric variables and Pearson's chi-square test for categorical data. Each correlate of PA was entered into a sex-specific bivariate logistic regression analysis that separately predicted the fulfilment of the HEPA and Fitness Recommendations. The statistical criterion of $p \leq 0.20$ in bivariate analyses was used to select correlates for the inclusion into a final multivariate logistic regression model (Tabachnick and Fidell 2007). The significance level was set at 0.05 . All logistic regression analyses were adjusted for the clustering of participants according to school. We finally repeated the multivariate analysis for the HEPA Recommendation, excluding the adolescents fulfilling the Fitness Recommendation and vice versa to prevent an overlap of the two recommendations. The analyses were performed using SPSS for Windows, version 14.0.

\section{Results}

Table 1 presents the distribution of the fulfilment of the two recommendations for girls and boys. Boys were more physically active compared to girls, with a significant difference observed only for the Fitness Recommendation.

Table 2 shows the sex-specific distribution of potential correlates of PA behaviour. We observed significant sex differences in weight status, self-rated health, sedentary behaviour and membership in a sports club.

There was, with one exception, no significant relationship between PA variables and the HEPA Recommendation in boys (see Table 3). However, a past or never membership in a sports club sharply reduced the chance to fulfil this recommendation.

Higher scores of self-efficacy and a more frequent use of behavioural change strategies increased the fulfilment of the Fitness Recommendation. To evaluate the multivariate models, we computed Nagelkerkes $\mathrm{R}^{2}$. The variance explained by the model for the HEPA Recommendation was 0.41 . The corresponding $\mathrm{R}^{2}$ for the Fitness Recommendation was 0.54 .

The association between the HEPA Recommendation and the Fitness Recommendation and potential correlates for girls is displayed in Table 4. Girls fulfiled the Fitness Recommendation in favour of a past sports club member-

Table 1 Sample characteristics by sex

\begin{tabular}{|c|c|c|c|}
\hline Characteristics & Boys & Girls & p-value \\
\hline & $\mathrm{n}=263$ & $\mathrm{n}=261$ & \\
\hline \multicolumn{4}{|c|}{ HEPA recommendation ${ }^{\mathrm{a}}(\%)$} \\
\hline No & 61.2 & 68.2 & \multirow[t]{2}{*}{$\mathrm{p}=0.094$} \\
\hline Yes & 38.8 & 31.8 & \\
\hline \multicolumn{4}{|c|}{ Fitness recommendation ${ }^{\mathrm{b}}(\%)$} \\
\hline No & 38.4 & 60.2 & \multirow[t]{2}{*}{$\mathrm{p}=0.000$} \\
\hline Yes & 61.6 & 39.8 & \\
\hline \multicolumn{4}{|l|}{ Age } \\
\hline Mean (SD) & $15.07(0.65)$ & $15.03(0.70)$ & $\mathrm{p}=0.511$ \\
\hline
\end{tabular}

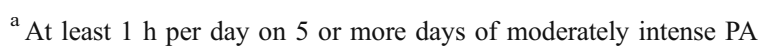

${ }^{\mathrm{b}}$ At least three sessions per week of vigorously intense PA that lasted 20 min or more 
Table 2 Distribution of potential correlates of PA behaviour
${ }^{\mathrm{a}}$ Family Affluence Scale (FAS) as a proxy measure of SES. The FAS was derived by identifying the levels of wealth based upon four 'family items'. The pattern of answers can be classified as low, middle and high SES according to a summation score

${ }^{\mathrm{b}}$ German-specific age- and genderspecific cutoff values were applied to BMI

${ }^{\mathrm{c}}$ A 5-point scale was applied (range 1-5)

${ }^{\mathrm{d}}$ Going by bike or on foot was considered active commuting, while going by bus, driving a car or driving a scooter was considered non-active commuting

${ }^{\mathrm{e}}$ The summation of time watching $\mathrm{TV}$, using the computer and doing one's homework resulted in the following tertiles based on all participants (low: $\leq 3.9 \mathrm{~h} /$ day; middle: $>3.9-5.9$; high: $>5.9$ )

\begin{tabular}{|c|c|c|c|}
\hline Variables & Boys & Girls & p-value \\
\hline Demographic/biological & $\mathrm{n}=263$ & $\mathrm{n}=261$ & \\
\hline \multicolumn{4}{|l|}{ Type of school (\%) } \\
\hline Hauptschule (secondary general school) & 16.7 & 21.1 & \multirow[t]{3}{*}{$\mathrm{p}=0.343$} \\
\hline Realschule (intermediate secondary school) & 33.1 & 34.1 & \\
\hline Gymnasium (grammar school) & 50.2 & 44.8 & \\
\hline \multicolumn{4}{|l|}{ Socioeconomic status $^{\mathrm{a}}(\%)$} \\
\hline Low & 13.3 & 18.0 & \multirow[t]{3}{*}{$\mathrm{p}=0.067$} \\
\hline Middle & 44.5 & 49.0 & \\
\hline High & 42.2 & 33.0 & \\
\hline \multicolumn{4}{|l|}{ Weight status $(\mathrm{BMI})^{\mathrm{b}}(\%)$} \\
\hline Normal & 88.6 & 95.0 & \multirow[t]{3}{*}{$\mathrm{p}=0.014$} \\
\hline Overweight & 7.6 & 2.3 & \\
\hline Obese & 3.8 & 2.7 & \\
\hline \multicolumn{4}{|l|}{ Psychological } \\
\hline Self-efficacy ${ }^{\mathrm{c}}[$ mean (SD)] & $3.26(0.73)$ & $3.07(0.78)$ & $\mathrm{p}=0.004$ \\
\hline Perceived pros ${ }^{c}[$ mean (SD)] & $3.64(0.68)$ & $3.53(0.77)$ & $\mathrm{p}=0.080$ \\
\hline Perceived cons ${ }^{c}[$ mean (SD)] & $2.22(0.60)$ & $2.38(0.63)$ & $\mathrm{p}=0.002$ \\
\hline 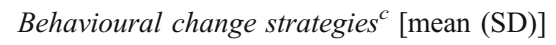 & $2.82(0.69)$ & $2.87(0.68)$ & $\mathrm{p}=0.450$ \\
\hline Cognitive change strategies ${ }^{c}$ [mean (SD)] & $2.52(0.71)$ & $2.64(0.72)$ & $\mathrm{p}=0.068$ \\
\hline \multicolumn{4}{|l|}{ Self-rated health $(\%)$} \\
\hline Poor & 0.8 & 1.9 & \multirow{4}{*}{$\mathrm{P}=0.000$} \\
\hline Fair & 7.2 & 10.7 & \\
\hline Good & 56.3 & 68.2 & \\
\hline Excellent & 35.7 & 19.2 & \\
\hline \multicolumn{4}{|l|}{ Behavioural } \\
\hline \multicolumn{4}{|l|}{ Membership in sports club (\%) } \\
\hline No & 9.9 & 13.8 & \multirow{3}{*}{$\mathrm{P}=0.000$} \\
\hline Past & 24.3 & 45.6 & \\
\hline Yes & 65.8 & 40.6 & \\
\hline \multicolumn{4}{|l|}{ Active commuting to school ${ }^{\mathrm{d}}(\%)$} \\
\hline No & 18.6 & 20.7 & \multirow[t]{2}{*}{$\mathrm{p}=0.553$} \\
\hline Yes & 81.4 & 79.3 & \\
\hline \multicolumn{4}{|l|}{ Sedentary behaviour ${ }^{\mathrm{e}}(\%)$} \\
\hline Low & 27.8 & 39.1 & \multirow{3}{*}{$\mathrm{p}=0.022$} \\
\hline Middle & 35.7 & 31.0 & \\
\hline High & 36.5 & 29.9 & \\
\hline
\end{tabular}

ship. With respect to the HEPA Recommendation, a past or never membership in a sports club markedly decreased the chance to be sufficiently active. Other variables were not significantly associated with PA recommendations. The variance explained by the model for the HEPA Recommendation was 0.12 . The corresponding $\mathrm{R}^{2}$ for the Fitness Recommendation was 0.41 (Table 5).

The overlap between boys and girls fulfilling the two PA recommendations was high. For example, $54 \%$ of the boys who fulfilled the Fitness Recommendation concurrently fulfilled the HEPA Recommendation. In comparison, only $40.4 \%$ of the girls who fulfilled the Fitness Recommenda- tion concurrently fulfilled the HEPA Recommendation (data not shown). Therefore, we verified our results with respect to the HEPA Recommendation by excluding all participants who fulfilled the Fitness Recommendation. A similar pattern was found, but we no longer found a significant association for girls. In boys, we additionally observed a statistically significant negative relationship between a high level of sedentary behaviour and fulfilment of the HEPA Recommendation. In a similar fashion, we repeated the multivariate analysis for the Fitness Recommendation by excluding these adolescents who did not fulfil the HEPA Recommendation. The significant odds 
Table 3 Odds ratio of fulfilling two different PA recommendations for boys

\begin{tabular}{|c|c|c|c|c|}
\hline \multirow[b]{2}{*}{ Correlates } & \multicolumn{2}{|c|}{ HEPA recommendation } & \multicolumn{2}{|c|}{ Fitness-recommendation } \\
\hline & $\begin{array}{l}\text { Unadjusted } \mathrm{OR}^{\mathrm{a}} \\
(95 \% \mathrm{CI})\end{array}$ & $\begin{array}{l}\text { Adjusted } \mathrm{OR}^{\mathrm{b}} \\
(95 \% \mathrm{CI})\end{array}$ & $\begin{array}{l}\text { Unadjusted } \mathrm{OR}^{\mathrm{a}} \\
(95 \% \mathrm{CI})\end{array}$ & $\begin{array}{l}\text { Adjusted OR }{ }^{b} \\
(95 \% \text { CI })\end{array}$ \\
\hline \multicolumn{5}{|l|}{ Demographic/biological } \\
\hline \multicolumn{5}{|l|}{ Type of school } \\
\hline Hauptschule (secondary general school) & $1.5(0.8-3.0)$ & - & $1.2(0.6-2.5)$ & - \\
\hline Realschule (intermediate secondary school) & $1.2(0.7-2.1)$ & - & $0.9(0.5-1.6)$ & - \\
\hline Gymnasium (grammar school) (referent) & 1.0 & - & 1.0 & - \\
\hline \multicolumn{5}{|l|}{ Socioeconomic status ${ }^{\mathrm{c}}$} \\
\hline Low & $0.8(0.4-1.8)$ & - & $0.8(0.4-1.7)$ & $2.7(0.8-8.8)$ \\
\hline Middle & $0.8(0.5-1.4)$ & - & $0.7(0.4-1.2)$ & $1.3(0.6-2.8)$ \\
\hline High (referent) & 1.0 & - & 1.0 & $1.0(0.8-8.8)$ \\
\hline \multicolumn{5}{|l|}{ Weight status $(\mathrm{BMI})^{\mathrm{d}}$} \\
\hline Normal (referent) & 1.0 & 1.0 & 1.0 & 1.0 \\
\hline Overweight & $0.4(0.1-1.1)$ & $0.6(0.2-2.1)$ & $0.9(0.3-2.2)$ & $1.4(0.4-4.8)$ \\
\hline Obese & $0.4(0.1-1.8)$ & $0.9(0.1-7.0)$ & $0.2(0.1-0.96)$ & $0.5(0.1-4.1)$ \\
\hline \multicolumn{5}{|l|}{ Psychological } \\
\hline Self-efficacy ${ }^{e}($ referent $=1)$ & $1.8(0.8-4.1)$ & $0.6(0.2-1.6)$ & $5.3(2.4-12.0)$ & $3.1(1.0-9.5)^{*}$ \\
\hline Perceived pros $^{e}$ (referent $\left.=1\right)$ & $10.3(1.3-79,3)$ & $5.1(0.5-49.2)$ & $5.5(1.7-17.5)$ & $0.7(0.1-3.0)$ \\
\hline Perceived cons $^{e}($ referent $=1)$ & $0.6(0.4-1.1)$ & $0.7(0.4-1.5)$ & $0.6(0.3-0.95)$ & $0.8(0.4-1.7)$ \\
\hline Behavioural change strategies ${ }^{e}($ referent $=1)$ & $1.9(1.1-3.3)$ & $1.2(0.6-2.5)$ & $3.5(2.0-6.1)$ & $2.7(1.1-6.4)^{*}$ \\
\hline Cognitive change strategies ${ }^{e}$ (referent $=1$ ) & $1.3(0.8-2.2)$ & - & $1.8(1.1-3.0)$ & $1.1(0.5-2.5)$ \\
\hline \multicolumn{5}{|l|}{ Self-rated health } \\
\hline Poor/fair & $0.3(0.1-1.0)$ & $0.4(0.1-1.6)$ & $0.6(0.2-1.3)$ & $1.8(0.5-6.8)$ \\
\hline Good/excellent (referent) & 1.0 & 1.0 & 1.0 & 1.0 \\
\hline \multicolumn{5}{|l|}{ Behavioural } \\
\hline \multicolumn{5}{|l|}{ Membership in sports club } \\
\hline No & $0.3(0.1-0.8)$ & $1.9(0.5-6.8)$ & $0.04(0.0-0.1)$ & $0.1(0.01-0.3)^{*}$ \\
\hline Past & $0.4(0.2-0.8)$ & $1.5(0.7-3.5)$ & $0.2(0.1-0.3)$ & $0.2(0.1-0.5)^{*}$ \\
\hline Yes (referent) & 1.0 & 1.0 & 1.0 & 1.0 \\
\hline \multicolumn{5}{|l|}{ Active commuting to school ${ }^{\mathrm{f}}$} \\
\hline No & $1.0(0.5-1.9)$ & - & $0.6(0.3-1.1)$ & $0.7(0.3-1.7)$ \\
\hline Yes (referent) & 1.0 & - & 1.0 & 1.0 \\
\hline \multicolumn{5}{|l|}{ Sedentary behaviour ${ }^{\mathrm{g}}$} \\
\hline Low (referent) & 1.0 & 1.0 & 1.0 & 1.0 \\
\hline Middle & $0.7(0.4-1.4)$ & $0.9(0.4-2.0)$ & $0.7(0.3-1.3)$ & $1.2(0.5-2.9)$ \\
\hline High & $0.4(0.2-0.8)$ & $0.6(0.3-1.4)$ & $0.4(0.2-0.8)$ & $1.1(0.5-2.5)$ \\
\hline
\end{tabular}

${ }^{a}$ Adjusted for clustering of children by school

${ }^{\mathrm{b}}$ Adjusted for clustering of children by school, the days of vigorous PA with continuous bouts of 20 min or the days of moderate to vigorous PA with an accumulated $60 \mathrm{~min}$ and correlates that were significant $(\mathrm{p}<0.20$ related to the dependent variable in bivariate logistic analyses)

${ }^{\mathrm{c}}$ Family Affluence Scale (FAS) as a proxy measure of SES. The FAS was derived by identifying the levels of wealth based upon four 'family items'. The pattern of answers can be classified as low, middle and high SES according to a summation score

${ }^{\mathrm{d}}$ German-specific age- and gender-specific cutoff values were applied to BMI

e Psychosocial correlates of pros and cons were dichotomised as (1) "never", "seldom" (change strategies); "not at all confident", "somewhat confident" (self-efficacy); "not important", "a little bit important" (pros and cons) and (2) "occasionally", "often", "repeatedly" (change strategies); "moderately confident", "very confident", "completely confident" (self-efficacy); "somewhat important", "quite important”, "extremely important" (pros and cons)

${ }^{\mathrm{f}}$ Going by bike or on foot was considered active commuting, while going by bus, driving a car or driving a scooter was considered non-active commuting

${ }^{\mathrm{g}}$ The summation of time watching TV, using the computer and doing one's homework resulted in the following tertiles based on all participants (low: $\geq 3.9$ h/day; middle: $>3.9-5.9$; high: $>5.9$ )

${ }^{*} \mathrm{p}<0.05$ is presented in bold font for the adjusted model 
Table 4 Odds ratio of fulfilling two different PA recommendations for girls

\begin{tabular}{|c|c|c|c|c|}
\hline \multirow[b]{2}{*}{ Correlates } & \multicolumn{2}{|c|}{ HEPA recommendation } & \multicolumn{2}{|c|}{ Fitness recommendation } \\
\hline & $\begin{array}{l}\text { Unadjusted } \mathrm{OR}^{\mathrm{a}} \\
(95 \% \mathrm{CI})\end{array}$ & $\begin{array}{l}\text { Adjusted OR }{ }^{\mathrm{b}} \\
(95 \% \mathrm{CI})\end{array}$ & $\begin{array}{l}\text { Unadjusted } \mathrm{OR}^{\mathrm{a}} \\
(95 \% \mathrm{CI})\end{array}$ & $\begin{array}{l}\text { Adjusted OR }{ }^{b} \\
(95 \% \mathrm{CI})\end{array}$ \\
\hline \multicolumn{5}{|l|}{ Demographic/biological } \\
\hline \multicolumn{5}{|l|}{ Type of school } \\
\hline Hauptschule (secondary general school) & $1.2(0.6-2.4)$ & - & $0.5(0.3-0.9)$ & $1.2(0.5-2.9)$ \\
\hline Realschule (intermediate secondary school) & $0.8(0.5-1.5)$ & - & $0.4(0.2-0.8)$ & $0.6(0.3-1.2)$ \\
\hline Gymnasium (grammar school) (referent) & 1.0 & - & 1.0 & 1.0 \\
\hline \multicolumn{5}{|l|}{ Socioeconomic status ${ }^{\mathrm{c}}$} \\
\hline Low & $1.1(0.5-2.3)$ & - & $0.5(0.2-1.1)$ & $1.0(0.4-2.9)$ \\
\hline Middle & $0.9(0.5-1.6)$ & - & $0.7(0.4-1.3)$ & $1.3(0.6-2.6)$ \\
\hline High (referent) & 1.0 & - & 1.0 & 1.0 \\
\hline \multicolumn{5}{|l|}{ Weight status $(\mathrm{BMI})^{\mathrm{d}}$} \\
\hline Normal (referent) & 1.0 & - & 1.0 & - \\
\hline Overweight & $1.0(0.1-1.1)$ & - & $0.3(0.0-2.6)$ & - \\
\hline Obese & 0.0 (0.0-une) & - & $2.1(0.5-9.6)$ & - \\
\hline \multicolumn{5}{|l|}{ Psychological } \\
\hline Self-efficacy ${ }^{e}($ referent $=1)$ & $1.0(0.6-2.0)$ & - & $4.2(2.0-8.7)$ & $2.3(0.8-6.2)$ \\
\hline Perceived pros $^{e}$ (referent $\left.=1\right)$ & $1.0(0.4-2.3)$ & - & $2.7(1.0-6.8)$ & $0.8(0.2-2.8)$ \\
\hline Perceived cons $^{e}$ (referent $\left.=1\right)$ & $0.9(0.5-1.5)$ & - & $0.7(0.4-1.2)$ & $1.2(0.6-2.2)$ \\
\hline Behavioural change strategies ${ }^{e}($ referent $=1)$ & $1.8(0.9-3.4)$ & $1.6(0.8-3.1)$ & $2.8(1.5-5.3)$ & $1.6(0.7-3.7)$ \\
\hline Cognitive change strategies ${ }^{e}$ (referent $=1$ ) & $1.1(0.6-1.8)$ & - & $1.3(0.8-2.2)$ & - \\
\hline \multicolumn{5}{|l|}{ Self-rated health } \\
\hline Poor/fair & $0.8(0.4-1.8)$ & - & $0.6(0.3-1.4)$ & - \\
\hline Good/excellent (referent) & 1.0 & - & 1.0 & - \\
\hline \multicolumn{5}{|l|}{ Behavioural } \\
\hline \multicolumn{5}{|l|}{ Membership in sports club } \\
\hline No & $0.6(0.2-1.4)$ & $1.1(0.4-2.8)$ & $0.2(0.1-0.2)$ & $0.2(0.1-0.5) *$ \\
\hline Past & $1.0(0.6-1.7)$ & $2.0(1.0-4.0)^{*}$ & $0.1(0.1-0.2)$ & $0.1(0.1-0.3)^{*}$ \\
\hline Yes (referent) & 1.0 & 1.0 & 1.0 & 1.0 \\
\hline \multicolumn{5}{|l|}{ Active commuting to school ${ }^{\mathrm{f}}$} \\
\hline No & $0.6(0.3-1.3)$ & $0.6(0.3-1.3)$ & $0.7(0.4-1.3)$ & - \\
\hline Yes (referent) & 1.0 & 1.0 & 1.0 & - \\
\hline \multicolumn{5}{|l|}{ Sedentary behaviour ${ }^{\mathrm{g}}$} \\
\hline Low (referent) & 1.0 & 1.0 & 1.0 & 1.0 \\
\hline Middle & $0.6(0.3-1.2)$ & $0.7(0.4-1.4)$ & $0.8(0.5-1.5)$ & $0.9(0.4-1.9)$ \\
\hline High & $0.8(0.5-1.6)$ & $1.0(0.5-1.9)$ & $0.6(0.3-1.1)$ & $0.7(0.3-1.6)$ \\
\hline
\end{tabular}

${ }^{\mathrm{a}}$ Adjusted for clustering of children by school

${ }^{\mathrm{b}}$ Adjusted for clustering of children by school, the days of vigorous PA with continuous bouts of 20 min or the days of moderate to vigorous PA with an accumulated $60 \mathrm{~min}$ and correlates that were significant $(\mathrm{p}<0.20$ related to the dependent variable in bivariate logistic analyses)

${ }^{\mathrm{c}}$ Family Affluence Scale (FAS) as a proxy measure of SES. The FAS was derived by identifying the levels of wealth based upon four 'family items'. The pattern of answers can be classified as low, middle and high SES according to a summation score

${ }^{\mathrm{d}}$ German-specific age- and gender-specific cutoff values were applied to BMI

e Psychosocial correlates of pros and cons were dichotomised as (1) "never", "seldom" (change strategies); "not at all confident", "somewhat confident" (self-efficacy); "not important", "a little bit important" (pros and cons) and (2) "occasionally", "often", "repeatedly" (change strategies); "moderately confident", "very confident", "completely confident" (Self-efficacy); "somewhat important", "quite important", "extremely important" (pros and cons)

${ }^{\mathrm{f}}$ Going by bike or on foot was considered active commuting, while going by bus, driving a car or driving a scooter was considered non-active commuting

${ }^{\mathrm{g}}$ The summation of time watching TV, using the computer and doing one's homework resulted in the following tertiles based on all participants (low: $\leq 3.9$ h/day; middle: $>3.9-5.9$; high: $>5.9$ )

${ }^{*} \mathrm{p}<0.05$ is presented in bold font for the adjusted model 
Table 5 Adjusted odds ratio ( $95 \%$ CI) of fulfilling only one of the two different PA recommendations

\begin{tabular}{|c|c|c|c|c|}
\hline \multirow[b]{2}{*}{ Correlates } & \multicolumn{2}{|c|}{ HEPA recommendation } & \multicolumn{2}{|c|}{ Fitness recommendation } \\
\hline & Boys $(\mathrm{n}=101)$ & Girls $(n=157)$ & Boys $(n=161)$ & Girls $(n=178)$ \\
\hline \multicolumn{5}{|l|}{ Demographic/biological } \\
\hline \multicolumn{5}{|l|}{ Type of school } \\
\hline Hauptschule (secondary general school) & - & - & - & $0.7(0.2-2.1)$ \\
\hline Realschule (intermediate secondary school) & - & - & - & $0.4(0.2-0.9)^{*}$ \\
\hline Gymnasium (grammar school) (referent) & - & - & - & 1.0 \\
\hline \multicolumn{5}{|l|}{ Socioeconomic status ${ }^{\mathrm{c}}$} \\
\hline Low & - & - & $1.6(0.4-6.1)$ & $1.2(0.3-3.9)$ \\
\hline Middle & - & - & $0.9(0.4-6.1)$ & $0.9(0.4-2.2)$ \\
\hline High (referent) & - & - & 1.0 & 1.0 \\
\hline \multicolumn{5}{|l|}{ Weight status $(\mathrm{BMI})^{\mathrm{d}}$} \\
\hline Normal (referent) & 1.0 & - & 1.0 & - \\
\hline Overweight & $1.0(0.1-12.7)$ & - & $1.6(0.4-6.1)$ & - \\
\hline Obese & 0.0 (0.0-infinite) & - & $0.3(0.0-4.5)$ & - \\
\hline \multicolumn{5}{|l|}{ Psychological } \\
\hline Self-efficacy ${ }^{e}($ referent $=1)$ & $0.2(0.03-1.5)$ & - & $4.8(1.1-20.6)^{*}$ & $2.5(0.8-8.4)$ \\
\hline Perceived pros $^{e}($ referent $=1)$ & 0.0 (0.0-une) & - & $1.0(0.2-5.5)$ & $2.4(0.4-13.6)$ \\
\hline Perceived $\operatorname{cons}^{e}($ referent $=1)$ & $0.4(0.1-1.7)$ & - & $0.6(0.2-1.4)$ & $0.8(0.4-1.7)$ \\
\hline Behavioural change strategies ${ }^{e}$ (referent $=1$ ) & $2.3(0.6-9.6)$ & $2.2(0.9-5.1)$ & $3.9(1.4-10.5)^{*}$ & $1.8(0.7-4.6)$ \\
\hline Cognitive change strategies $^{e}$ (referent $=1$ ) & - & - & $1.1(0.4-2.8)$ & - \\
\hline \multicolumn{5}{|l|}{ Self-rated health } \\
\hline Poor/fair & $0.4(0.03-4.2)$ & - & $1.6(0.4-6.4)$ & - \\
\hline Good/excellent (referent) & 1.0 & - & 1.0 & - \\
\hline \multicolumn{5}{|l|}{ Behavioural } \\
\hline \multicolumn{5}{|l|}{ Membership in sports club } \\
\hline No & $2.3(0.4-14.6)$ & $1.2(0.3-4.6)$ & $0.1(0.0-0.4)^{*}$ & $0.2(0.1-0.8)^{*}$ \\
\hline Past & $0.9(0.2-3.9)$ & $2.5(0.9-7.0)$ & $0.2(0.1-0.6)^{*}$ & $0.2(0.1-0.5)^{*}$ \\
\hline Yes (referent) & 1.0 & 1.0 & 1.0 & 1.0 \\
\hline \multicolumn{5}{|l|}{ Active commuting to school ${ }^{\mathrm{f}}$} \\
\hline No & - & $0.7(0.3-1.8)$ & $0.4(0.2-1.1)$ & - \\
\hline Yes (referent) & - & 1.0 & 1.0 & - \\
\hline \multicolumn{5}{|l|}{ Sedentary behaviour ${ }^{\mathrm{g}}$} \\
\hline Low (referent) & 1.0 & 1.0 & 1.0 & 1.0 \\
\hline Middle & $0.6(0.1-2.8)$ & $0.9(0.3-2.1)$ & $1.2(0.4-3.3)$ & $0.9(0.4-2.2)$ \\
\hline High & $0.1(0.02-0.8)^{*}$ & $1.3(0.5-3.2)$ & $0.8(0.3-2.2)$ & $0.9(0.4-2.4)$ \\
\hline
\end{tabular}

${ }^{\mathrm{a}}$ Adjusted for clustering of children by school

${ }^{\mathrm{b}}$ Adjusted for clustering of children by school, the days of vigorous PA with continuous bouts of 20 min or the days of moderate to vigorous PA with an accumulated $60 \mathrm{~min}$ and correlates that were significant $(\mathrm{p}<0.20$ related to the dependent variable in bivariate logistic analyses)

${ }^{\mathrm{c}}$ Family Affluence Scale (FAS) as a proxy measure of SES. The FAS was derived by identifying the levels of wealth based upon four 'family items'. The pattern of answers can be classified as low, middle and high SES according to a summation score

${ }^{\mathrm{d}}$ German-specific age- and gender-specific cutoff values were applied to BMI

e Psychosocial correlates of pros and cons were dichotomised as (1) "never", "seldom" (change strategies); "not at all confident", "somewhat confident" (Self-efficacy); "not important", "a little bit important" (pros and cons) and (2) "occasionally", "often", "repeatedly" (change strategies); "moderately confident", "very confident", "completely confident" (self-efficacy); "somewhat important", "quite important", "extremely important" (pros and cons)

${ }^{\mathrm{f}}$ Going by bike or on foot was considered active commuting, while going by bus, driving a car or driving a scooter was considered non-active commuting ${ }^{\mathrm{g}}$ The summation of time watching TV, using the computer and doing one's homework resulted in the following tertiles based on all participants (low: $\leq 3.9$ h/day, middle: $>3.9-5.9$, high: $>5.9$ )

${ }^{*} \mathrm{p}<0.05$ is presented in bold font for the adjusted model 
ratios were confirmed and strengthened for boys. In girls, the significant associations were also confirmed, and in addition, it was shown that a lower level of education reduced the chance to be sufficiently active. The variance explained by these models confirmed previous findings [Nagelkerkes $\mathrm{R}^{2}$ for boys: 0.29 (HEPA) vs. 0.41 (Fitness); $\mathrm{R}^{2}$ for girls: 0.07 (HEPA) vs. 0.32 (Fitness)].

\section{Discussion}

Correlates of PA might be dependent on the type and/or intensity of PA. To contribute to a better understanding of these correlates, we examined whether a set of correlates differed between a recommendation of health-enhancing PA including PA of moderate intensity and a recommendation of fitness focusing only on vigorously intense exercise. The results of the present study provided some preliminary indication that correlates differ depending on specific recommendations in 14-16-year-old boys and girls. Moreover, some variability with regard to sex was observed.

In our study, no clear association was observed between PA and demographic/biological variables. We studied educational level, SES and BMI as potential correlates. Other studies also showed inconsistent findings for these associations (Biddle et al. 2005; Ekelund et al. 2004; Sallis et al. 2000). Contradictory findings for SES, especially in girls, have been observed (Biddle et al. 2005; Brodersen et al. 2007; Lampert et al. 2007; Richter 2005). We also obtained an association between educational level and Fitness Recommendation by additional analyses, which were restricted to girls who only fulfilled this recommendation. The complexity of SES and the problem of using different surrogates for SES might be the causes of the inconsistent findings (Sallis et al. 2000).

With regard to the psychological correlates, we observed some interesting results. Current studies showed that selfefficacy is a potential correlate of PA (Biddle et al. 2005). We found that only sufficiently active boys, based on the Fitness Recommendation, were statistically associated with higher self-efficacy. This result might be explained by the common finding that boys have higher scores of selfefficacy compared to girls (Patterson et al. 2006). This observation was also true for our own data (data not shown).

In our study, pros and cons were not significantly associated with either one of the recommendations. Both scales were highly skewed in the direction of social desirability. A sufficient differentiation was not possible. However, perceived pros and cons were shown to be inconsistently associated with PA (Sallis et al. 2000) in adolescents. However, Biddle et al. (2005) observed a strong relationship to perceived cons in girls. Moreover, the use of an overall scale for pros and cons instead of prominent pros and cons might have masked some specific associations in our study.

Consistent with our findings, there is evidence that behavioural change strategies have been more important for the actual behaviour change (Lewis et al. 2002; Maddison and Prapavessis 2006). We did not find an association between PA recommendations and the cognitive change strategies, because these are likely to be more important in shaping behaviour.

We did not observe any association between self-rated health and PA recommendations. Self-rated health has not been examined extensively in relation to PA behaviour, but Brodersen and colleagues (2005) reported that poor selfrated health is associated with lower PA in girls and boys. The lack of an association in our study might be due to the dichotomous criterion of PA. Moreover, most of the girls and boys reported good or excellent health. This might have masked real differences.

For behavioural attributes, we examined the membership in a sports club, sedentary behaviour and active commuting as potential correlates. The membership in a sports club displayed the highest positive correlation to fulfilling the Fitness Recommendation for boys and girls in our study and warranted review in greater detail. An Icelandic study found that membership in a sports club can explain the large PA difference between boys and girls, but if a girl is a member of a sports club she also would be more physically active (Vilhjalmsson and Kristjansdottir 2003). A systematic review also highlighted the importance of the organised sports involvement for girls' PA behaviour (Biddle et al. 2005). Our opposing finding of the association between membership in a sports club and the fulfilment of the HEPA Recommendation also warrants discussion. Within our entire study, we used a more detailed PA questionnaire, which showed that a high amount of overall PA was derived from non-organised sport activities. In addition, Wickel and Eisenmann (2007) showed that moderate-to-vigorous PA is determined by a substantial amount of organised activities. However, unstructured PA contributed to the largest partition of moderate-to-vigorous PA. Consequently, meeting the HEPA Recommendation is primarily determined by unstructured PA, and membership in a sports club did not explain this type of PA.

Furthermore, we did not find a distinct relationship amng sedentary behaviour, active commuting and PA recommendations. For sedentary behaviour, this finding is in line with recent studies that emphasised that this association is very small and that there is time for both sedentary and PA throughout the day (Biddle 2007; Jago et al. 2005). With regard to active commuting, current studies have shown that children and adolescents who travel to school by bike or on foot present more overall activity compared to those 
who travel by car (Cooper et al. 2005). The lack of an association between PA recommendations and active commuting in our study might have been caused by the high amount of active commuters in the present sample and the short distances travelled to school (data not shown).

All in all, a high proportion of variance remained unexplained in the multivariate models. Other variables have to be examined to explain PA behaviour. In addition, we observed a higher explanation of variance in the multivariate model for the Fitness Recommendation compared to the HEPA Recommendation in boys and girls. This finding might indicate a stronger association of the HEPA Recommendation with environmental correlates. Recent studies have supported this assumption (Ball et al. 2006; Giles-Corti and King 2009). Unfortunately, environmental variables (e.g., neighbourhood environment) were not examined in this study, although they may have masked interesting differences between the two PA recommendations. Furthermore, the comparison of the multivariate models between girls and boys showed a relatively higher explanation of the variance in boys. One possible explanation may also be attributed to the fact that girls' PA correlates clustered around positive psychology (e.g., perceived competence, attractiveness and physical selfworth) (Biddle et al. 2005); however, we did not examine these variables.

The present study had some limitations. First, a crosssectional study provided the weakest evidence to infer causality. Second, there was a substantial overlap between the two PA recommendations. The HEPA Recommendation included, by definition, vigorously intense PA. Consequently, the idea of comparing distinct types of PA recommendations was restricted. This makes conclusions more difficult. However, with our analyses, which were restricted to pupils who met only one of the recommendations, we confirmed our prior findings. Third, the applied scales referred to the examination of PA with a broad definition ("HEPA concept") and were not explicitly developed to define exercise behaviour. The use of behaviour-specific scales might have resulted in altered findings. Fourth, this paper reported the results of a study to explore the transtheoretical model of behaviour change in the context of PA behaviour (Bucksch et al. 2008), and therefore important correlates of PA in adolescents (e.g., enjoyment, social support and environmental variables) (Sallis et al. 2000) were not included. Finally, we used only self-reported measurements. These instruments are prone to misclassification. This misclassification was especially relevant with regard to the self-reported PA, weight and height. We employed validated self-reported PA screening questionnaires (Prochaska et al. 2001). However, we found a sex difference for PA behaviour consistent with the literature (Jago et al. 2005; Sallis et al. 2000), and studies with the same assessment provide a similar prevalence for fulfiling the HEPA Recommendation (Richter and Settertobulte 2003). In contrast, we observed that the Fitness Recommendation was more often fulfilled than the HEPA Recommendation. This result resembled one representative German study and other North American studies (Lampert et al. 2007; Prochaska et al. 2001), but it was contradictory to findings utilising objective PA measurements (Pate et al. 2002). The difference in the prevalence estimates between the two recommendations might have been due to misclassification: underestimation of moderately intense PA and overestimation of vigorously intense PA (Sallis and Saelens 2000). In addition, the use of self-reported data on BMI is a source of misclassification. Sherry and colleagues (2007) found that a high amount of adolescents underestimate their overweight status assessed by self-reported weight and height. Consequently, research on the association between self-reported weight status and PA would be biased toward the unity.

In conclusion, the correlates of PA differed relative to the HEPA and Fitness Recommendations. Psychological and behavioural variables provided the basis for interventions with respect to vigorously intense PA ("exercise"). Environmental correlates were not included in the present study but might be crucial to explain and promote moderately intense PA behaviour.

Acknowledgements This study was financially supported by a grant from the University of Bremen.

Competing Interests The authors declare that they have no competing interests.

\section{References}

Ball K, Timperio AF, Crawford DA (2006) Understanding environmental influences on nutrition and physical activity behaviors: where should we look and what should we count? Int J Behav Nutr Phys Act 3:33

Biddle SJH (2007) Sedentary behavior. Am J Prev Med 33:502504

Biddle SJH, Whitehead SH, O'Donavon TM, Nevill ME (2005) Correlates of participation in physical activity for adolescent girls: a systematic review of recent literature. J Phys Act Health 2:423-434

Bös K, Heel J, Romahn N, Tittlbach S, Woll A, Worth A, Hölling H (2002) Untersuchungen zur Motorik im Rahmen des Kinder-und Jugendsurveys. Gesundheitswesen 64:S80-S87

Brodersen NH, Steptoe A, Williamson S, Wardle J (2005) Sociodemographic, developmental, environmental, and psychological correlates of physical activity and sedentary behavior at age 11 to 12. Ann Behav Med 29:2-11

Brodersen NH, Steptoe A, Boniface DR, Wardle J (2007) Trends in physical activity and sedentary behaviour in adolescence: ethnic and socioeconomic differences. Br J Sports Med 41:140-144

Bucksch J, Finne E, Kolip P (2008) Transtheoretical model in the context of physical activity in a school-based sample of German adolescents. Eur J Sport Sci 8:403-412 
Cavill N, Biddle S, Sallis JF (2001) Health enhancing physical activity for young people: statement of the United Kingdom expert consensus conference. Pediatr Exerc Sci 13:12-25

Cole TJ, Bellizzi MC, Flegal KM, Dietz WH (2000) Establishing a standard definition for child overweight and obesity worldwide: international survey. BMJ 320:1240-1243

Cooper AR, Andersen LB, Wedderkopp N, Page AS, Froberg K (2005) Physical activity levels of children who walk, cycle, or are driven to school. Am J Prev Med 29:179-184

Currie C, Samdal O, Boyce W, Smith R (2001) Health behaviour in school-aged children: a WHO cross-national study (HBSC), research protocol for the 2001/2002 survey. Child and Adolescent Health Research Unit. University of Edinburgh, Edinburgh

Currie C, Roberts C, Morgan A, Smith R, Settertobulte W, Samdal O, Barnekow Rasmussen V (eds) (2004) Young people's health in context. Health Behaviour in School-aged Children (HBSC) study: international report from the 2001/2002 survey. WHO Regional Office for Europe, Copenhagen

De Bourdeaudhuij I, Teixeira PJ, Cardon G, Deforche B (2005) Environmental and psychosocial correlates of physical activity in Portuguese and Belgian adults 12. Public Health Nutr 8:886-895

Ekelund U, Sardinha LB, Anderssen SA, Harro M, Franks PW, Brage S, Cooper AR, Andersen LB, Riddoch C, Froberg K (2004) Associations between objectively assessed physical activity and indicators of body fatness in 9- to 10-year-old European children: a population-based study from four distinct regions in Europe (the European Youth Heart Study). Am J Clin Nutr 80:584-590

Fuchs R, Schwarzer R (1994) Selbstwirksamkeit zur sportlichen Aktivität: Reliabilität und Validität eines neuen Messintruments. Zeitschrift für Differentielle und Diagnostische Psychologie $15: 141-154$

Giles-Corti B, King AC (2009) Creating active environments across the life course: "thinking outside the square". Br J Sports Med 43:109-113

Idler EL, Benyamini Y (1997) Self-rated health and mortality: a review of 27 community studies. J Health Soc Behav 38:21-37

Jago R, Anderson CB, Baranowski T, Watson K (2005) Adolescent patterns of physical activity differences by gender, day, and time of day. Am J Prev Med 28:447-452

Kromeyer-Hauschild K, Wabitsch M, Kunze D (2001) Perzentile für den Body Mass Index für Kinder im Alter von 0 bis 18 Jahren. Monatszeitschrift Kinderheilkunde 149:807-818

Lampert T, Mensink GB, Romahn N, Woll A (2007) Physical activity among children and adolescents in Germany. Results of the German Health Interview and Examination Survey for Children and Adolescents (KiGGS). Bundesgesundheitsblatt Gesundheitsforschung Gesundheitsschutz 50:634-642

Lewis BA, Marcus BH, Pate RR, Dunn AL (2002) Psychosocial mediators of physical activity behavior among adults and children. Am J Prev Med 23:26-35

Maddison R, Prapavessis H (2006) A longitudinal examination of exercise behavior among New Zealand adolescents: a test of the transtheoretical model. Pediatr Exerc Sci 18:351-363

Olds T, Ridley K, Wake M, Hesketh K, Waters E, Patton G, Williams J (2007) How should activity guidelines for young people be operationalised? Int J Behav Nutr Phys Act 4:43

Owen N, Humpel N, Leslie E, Bauman A, Sallis JF (2004) Understanding environmental influences on walking; Review and research agenda. Am J Prev Med 27:67-76

Pate RR (2007) Historical perspectives on physical activity, fitness, and health. In: Bouchard C, Blair SN, Haskell WL (eds) Physical activity and health. Human Kinetics, Champaign, pp 22-35
Pate RR, Freedson PS, Sallis JF, Taylor WC, Sirard J, Trost SG, Dowda M (2002) Compliance with physical activity guidelines: prevalence in a population of children and youth. Ann Epidemiol 12:303-308

Patterson E, McGeough D, Cannon E, Hagströmer M, Bergman P, Kearney J, Sjöström M (2006) Self-efficacy, stages of change, physical activity in Irish college students. J Public Health 14:81-86

Prochaska JO, Velicer WF (1997) The transtheoretical model of health behavior change. Am J Health Promot 12:38-48

Prochaska JJ, Sallis JF, Long B (2001) A physical activity screening measure for use with adolescents in primary care. Arch Pediatr Adolesc Med 155:554-559

Rhodes RE, Berry T, Naylor P-J, Wharf Higgins SJ (2004) Three-step validation of exercise behavior processes of change in an adolescent sample. Meas Phys Educ Exerc Sci 8:1-20

Richter M (2005) Gesundheit und Gesundheitsverhalten im Jugendalter: Der Einfluss sozialer Ungleichheit. VS-Verlag, Wiesbaden

Richter M, Settertobulte W (2003) Gesundheits-und Freizeitverhalten von Jugendlichen. In: Hurrelmann K, Klocke A, Melzer W, Ravens-Sieberer U (eds) Jugendgesundheitssurvey. Internationale Vergleichsstudie im Auftrag der Weltgesundheitsorganisation WHO. Juventa, Weinheim, pp 99-157

Sallis JF (2000) Age-related decline in physical activity: a synthesis of human and animal studies. Med Sci Sports Exerc 32:1598-1600

Sallis J, Patrick K (1994) Physical activity guidelines for adolescents: consensus statement. Pediatr Exerc Sci 6:302-314

Sallis JF, Saelens BE (2000) Assessment of physical activity by selfreport: status, limitations, and future directions. Res Q Exerc Sport 71:S1-S14

Sallis JF, Prochaska JJ, Taylor WC (2000) A review of correlates of physical activity of children and adolescents. Med Sci Sports Exerc 32:963-975

Sherry B, Jefferds ME, Grummer-Strawn LM (2007) Accuracy of adolescent self-report of height and weight in assessing overweight status: a literature review. Arch Pediatr Adolesc Med 161:1154-1161

Spink KS, Shields CA, Chad K, Odnokon P, Muhajarine N, Humbert L (2006) Correlates for structured and unstructured activity among sufficiently active youth and adolescents: a new approach to understanding physical activity. Pediatr Exerc Sci 18:203-215

Strong WB, Malina RM, Blimkie CJ, Daniels SR, Dishman RK, Gutin B, Hergenroeder AC, Must A, Nixon PA, Pivarnik JM, Rowland T, Trost S, Trudeau F (2005) Evidence based physical activity for school-age youth. J Pediatr 146:732-737

Tabachnick BG, Fidell LS (2007) Using multivariate statistics. Pearson Education, Boston

Timperio A, Ball K, Salmon J, Roberts R, Giles-Corti B, Simmons D, Baur LA, Crawford D (2006) Personal, family, social, and environmental correlates of active commuting to school. Am J Prev Med 30:45-51

Twisk JW (2001) Physical activity guidelines for children and adolescents: a critical review. Sports Med 31:617-627

Van Sluijs EM, McMinn AM, Griffin SJ (2007) Effectiveness of interventions to promote physical activity in children and adolescents: systematic review of controlled trials. BMJ 335:703-716

Vilhjalmsson R, Kristjansdottir G (2003) Gender differences in physical activity in older children and adolescents: the central role of organized sport. Soc Sci Med 56:363-374

Wickel EE, Eisenmann JC (2007) Contribution of youth sport to total daily physical activity among 6- to 12-year-old boys 2 . Med Sci Sports Exerc 39:1493-1500 